\title{
Relationship between house dust mite (HDM) allergen exposure level and inhaled corticosteroid dosage in HDM-sensitive asthma patients on a self management program
}

\author{
Marjolein P. de Vries ${ }^{a, *}$, Lisette van den Bemt ${ }^{b}$, Bart P.A. Thoonen ${ }^{b}$, \\ Jean W.M. Muris ${ }^{a}$, C.P. (Onno) van Schayck ${ }^{a}$
}
a Department of General Practice, Research Institute Caphri, Maastricht University, P.0. Box 616, 6200 MD Maastricht, The Netherlands
${ }^{\mathrm{b}}$ Department of General Practice, University Medical Center Nijmegen, P.O. Box (10\%, 6.,0) L $_{B}$
Nijmegen, The Netherlands

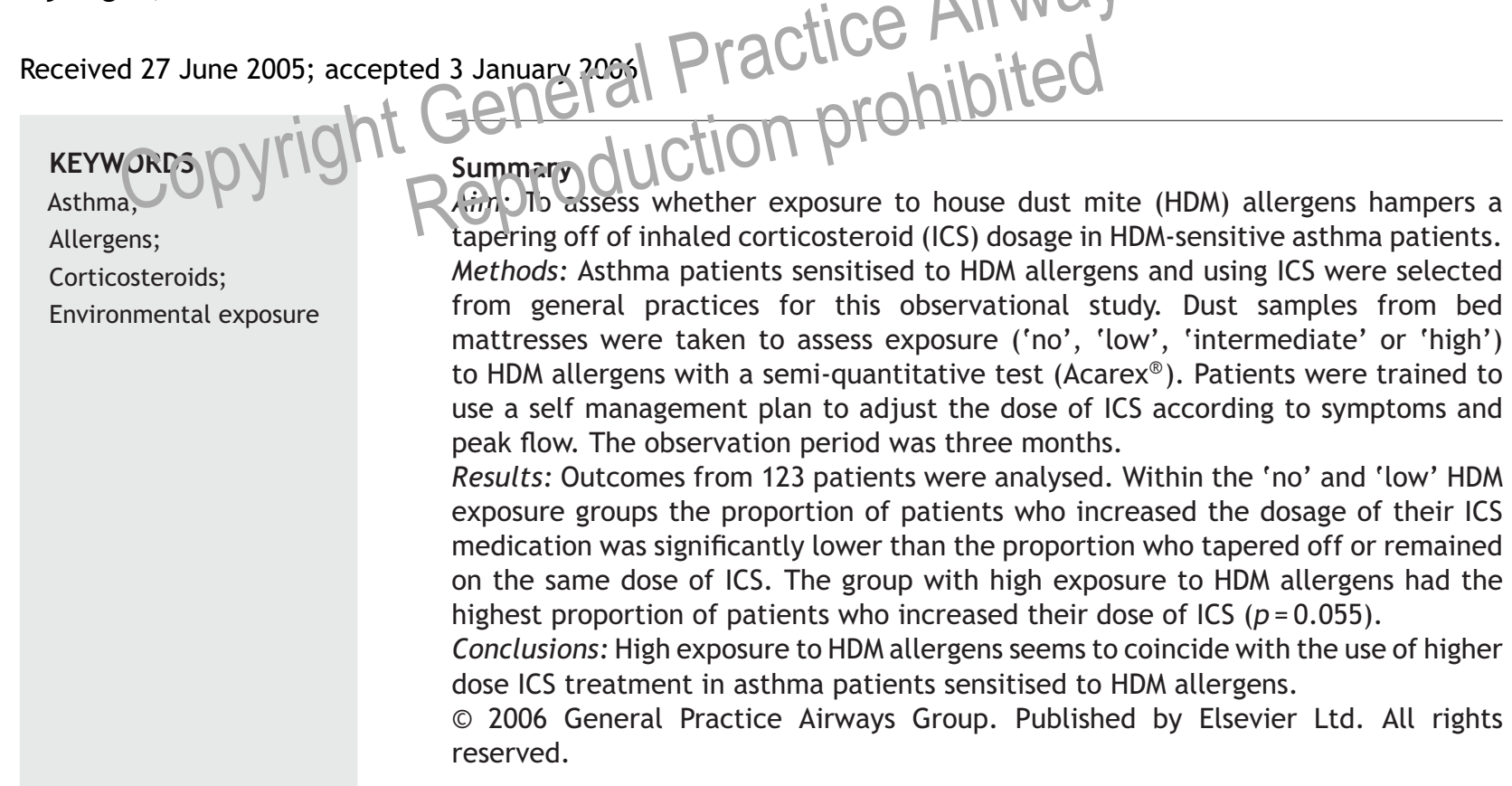

\footnotetext{
* Corresponding author. Tel.: +31 43 3882314;

fax: +31433619344 .

E-mail address: mleindevries@gmail.com (M.P. de Vries).
}

\section{Introduction}

Inflammation of the airways is a major underlying pathophysiological mechanism of asthma [1]. This 
inflammation leads to bronchoconstriction, which causes symptoms. Since inhaled corticosteroids (ICS) treat the inflammation of the airways, they can improve the long-term course of asthma [2-5]. For this reason ICS are the keystone in the pharmacological treatment of asthma. It is recommended that patients use the lowest possible dose of ICS that provides adequate control of the disease since harmful effects from long-term use of high dose ICS have been shown - for example, an increased risk of cataract [6] and effects on bone mineral density [7]. This emphasizes the importance of keeping the ICS dose at an optimally low level.

Self management programs or written action plans have been shown to lead to improved health outcomes [8]. In a self management program it is important that adequate behaviour is positively reinforced. If reinforcement occurs early in the learning process, the adequate behaviour is more easily maintained as subjects feel more selfefficacious. Self management programs can lead to a reduction of the amount of ICS dosage needed [9]. By adjusting the dose of ICS to their self-assessed degree of asthma, patients can use the lowest possible dose of ICS to gain adequate control. Some patients are not able to taper off their medication, possibly due to exposure to irritants. Exposure to relevant irritants such as allergens or norl-s?e ecitic irritants can cause inflammadtic n thid corisequently

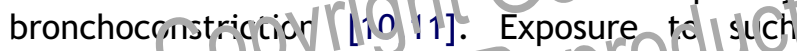
triggers inay be a reason for fies ding nigher medication or for difficulties encountered in trying to taper off medication. House dust mite (HDM) allergens have appeared to be one of the most important triggers in asthmatic patients. Therefore, high exposure to HDM allergens might be a reason why sensitised patients cannot taper off their dose of ICS adequately and why they experience problems with carrying out self management programs adequately.

In this study we wanted to investigate whether there is a relation between exposure to HDM allergens and the dosage of ICS needed in the context of a self management program in asthmatic patients sensitised to HDM allergens.

\section{Methods}

\section{Subjects}

Asthma patients in the south-eastern part of the Netherlands were enrolled from the registration networks of general practitioners (GPs) and by means of an open recruitment through advertisements in the local press. Recruitment took place all year round. Patients who were willing to participate were screened as regards inclusion and exclusion criteria.

Inclusion criteria were: age between 16 and 60 years; a GP-based diagnosis of asthma; sensitisation to HDM allergens; and requirement of ICS. The latter was defined according to the asthma treatment guidelines of the Dutch College of General Practitioners [12] which are comparable to the international GINA guidelines [13]. Sensitisation was determined with a Phadiatop ${ }^{\circledR}$ test (specific Immunoglobulin E (IgE) to a group of common aeroallergens). If positive, radio-allergo-sorbent tests (RASTs) were carried out for specific IgE for grasses, pollen, house dust mite, cat and dog. IgE levels below 0.35 kilo-units per litre (class 0 ) were considered to be negative.

Exclusion criteria were: serious diseases other than asthma with a low survival rate; other diseases which influence bronchial symptoms and/or lung function; an asthma exacerbation in the one month period preceding the start of the study; the use of oral steroids or inhaled cromoglycates; using HDMimpermeable covers for matiresses, billows and bedding; and allergy to dernostic pess while keeping these nets.

A cluestionnaire was ilsed to identify educational and employment (tevel, smoking habits and perceived airvay hyper-responsiveness.

The local Medical Ethical Committee approved the study. All patients agreed by written informed consent to participate in the study.

\section{Exposure to house dust mite allergens}

During a home visit a dust sample was taken from the patients' mattresses in a standardized way. Dust samples were taken from the mattresses with a vacuum cleaner (Bosch, 1300 watt) equipped with a nozzle containing a collector with a filter paper. Mattresses were totally vacuumed in a standardized way for a duration of 2 minutes per $\mathrm{m}^{2}$ of the mattress [14]. Both the upper surface of the patient's bare mattress and the upper surface of the partner's bare mattress (if a partner was present) were sampled.

A semi-quantitative test $\left(\right.$ Acarex $\left.^{\circledR}\right)$ was carried out with the dust sample to assess the guanine dosage. Guanine is an excretion product of mites. The Acarex ${ }^{\circledR}$ test gives reliable information about the presence of HDM allergens, including Der p1, one of the most common HDM allergens.

Exposure to HDM allergens was divided into the following categories; 'none', 'low', 'intermediate' and 'high'. These categories correspond roughly 
with the following concentrations of Der $\mathrm{p} 1$ per gram dust: 'none' $\leq 0.33 \mu \mathrm{g} / \mathrm{g}$; 'low' $0.33-2 \mu \mathrm{g} / \mathrm{g}$; 'intermediate' $2-8.33 \mu \mathrm{g} / \mathrm{g}$; and 'high' $\geq 8.33 \mu \mathrm{g} / \mathrm{g}$ [15-17].

\section{Medication use}

ICS usage at the start of the trial was categorised as: 'none' $(0 \mu \mathrm{g} /$ day); ' 'low dosage' (<400 $\mu \mathrm{g} /$ day); 'intermediate dosage' (from 400 to $800 \mu \mathrm{g} /$ day); and 'high dosage' ( $\geq 800 \mu \mathrm{g} /$ day). The total amount of ICS used daily was calculated as the amount of ICS per dose (in $\mu \mathrm{g}$ ) times the total number of puffs used per day. Dose equivalents for different types of ICS (drug molecules) and delivery devices were calculated. The dosage of metered dose inhalers was doubled in order to obtain equipotent dosages with dry powder inhalers [18]. The initial ICS dosage at the start of the trial was subtracted from the ICS dose after three months and the result was divided into the categories: 'tapered off'; 'equal dose'; or 'increased'.

Forced expiratory volume in one second $\left(\mathrm{FEV}_{1}\right)$ was measured at inclusion by means of a portable spirometer (Microloop II) at a lung function laboratory, and the $\mathrm{FEV}_{1} \%$ predicted was calculated.

Patients were trained to use a self manager ient plan to adjust the dose of IrS to sympiens and peak expiratory flow (FEF valuG GF's and trained research nurses lyave iniscructions arcerding to a stanclaraiced method. FFF cyas measured by means of a portable peak flow meter (Asmaplan+; Vitalograph ${ }^{\circledR}$, Buckingham, UK). Most participants used budesonide $200 \mu \mathrm{g}$ via Turbuhaler ${ }^{\circledR}$. Details of this plan are described by Thoonen et al. [9]. In Box 1 a summary of the self management plan is shown.

Information on symptoms, PEF, and medication use (ICS, bronchodilators and other medication) were recorded in diaries on a weekly basis.

The observation period was three months.

\section{Statistical analysis}

Baseline characteristics were tested with a Student's $t$-test, Chi-square, ANOVA or KruskalWallis test, to find significant differences in baseline characteristics between different HDM exposure groups and between the groups instructed by particular GPs or research nurses.

The proportion of patients who were able to taper off their ICS dose, who remained on the same dose, and who had to increase their ICS dose, were calculated for each HDM exposure group. Differences within each exposure group
Box 1: Summary of the self management plan

Step-up instructions

- Peak flow deteriorates $<80 \%$ PEFR $\geq 60 \%$ of Personal Best Value (PBV) for 2 out of 3 consecutive days:

Double budesonide dosage

In case of insufficient response within three weeks: again double budesonide dosage

- Peak flow deteriorates $<60 \%$ PEFR $\geq 40 \%$ of PBV for 2 out of 3 consecutive days:

Increase budesonide dosage to 800 micrograms b.i.d.

In case of insufficient response within two days: contact your GP

- Peak flow deteriorates $<40 \%$ of PBV: Immediately contact your GP to start a course of oral prednisolone

Step-down instructions

- Peak flow improves to $\geq 40 \%$ PEFR $<60 \%$ of PBV:

Continue the current-budespilide dosage until your PEFR is $580 \%$ of PBV

- Peak flin v' ir roves to $\geq 60 \%$ PEFR $<80 \%$ PBV: Continue the rurrent budesonide dosage until. our ictio is $>80 \%$ of PBV

- Pea < flow improves to $\geq 80 \%$ of PBV: Halve budesonide dosage when PEFR $\geq 80 \%$ for a period of six weeks

were compared with a chi-square test. Differences between the exposure groups for the number of patients who tapered off, remained on the same dose, and increased their ICS dose were compared with a test for linear trend.

Statistical significance was defined as $p$-value $<0.05$.

Statistical analyses were performed with SPSS for Windows, Version 11.0.

\section{Results}

One hundred and twenty-three patients were included.

Table 1 shows the baseline patient characteristics.

GPs instructed 31 participants, and two research nurses instructed the other 92 subjects. The instruction was standardised and the same for both groups. Patient characteristics did not 
Table 1 Baseline characteristics. Exposure to HDM allergens; number (\%)

\begin{tabular}{|c|c|c|c|c|c|}
\hline$N=123$ & None & Low & Intermediate & High & $p$-value \\
\hline Number of patients (\%) & $36(29.3 \%)$ & $38(30.9 \%)$ & $31(25.2 \%)$ & $18(14.6 \%)$ & \\
\hline Gender (male) (\%) & $19(52.8 \%)$ & $21(55.3 \%)$ & $16(51.6 \%)$ & $10(55.6 \%)$ & 0.88 \\
\hline Mean age (yrs) & 41.4 & 45.9 & 41.4 & 41.5 & 0.50 \\
\hline $\begin{array}{l}\text { Dose ICS at start ( } \mu \mathrm{g} / \text { day) } \\
\text { Categories: }(\%)\end{array}$ & & & & & 0.33 \\
\hline $\begin{array}{l}0 \mu \mathrm{g} \\
\text { low }(<400 \mu \mathrm{g}) \\
\text { intermediate }(400-800 \mu \mathrm{g}) \\
\text { high }(\geq 800 \mu \mathrm{g})\end{array}$ & $\begin{array}{r}3(8.3) \\
7(19.4) \\
14(38.9) \\
12(33.3)\end{array}$ & $\begin{array}{r}1(2.6) \\
6(15.8) \\
8(21.1) \\
23(60.5)\end{array}$ & $\begin{array}{r}3(9.7) \\
1(3.2) \\
11(35.5) \\
16(51.6)\end{array}$ & $\begin{array}{l}0(0.0) \\
1(5.6) \\
9(50.0) \\
8(44.4)\end{array}$ & \\
\hline Long acting bronchodilators & $9(25.0 \%)$ & $10(26.3 \%)$ & $7(22.6 \%)$ & $5(27.8 \%)$ & 0.78 \\
\hline $\mathrm{FEV}_{1} \%$ predicted & 90.5 & 88.6 & 90.4 & 92.0 & 0.64 \\
\hline $\begin{array}{l}\text { Smoking }(\%) \\
\text { Never } \\
\text { Ex } \\
\text { Current }\end{array}$ & $\begin{array}{r}25(69.4 \%) \\
9(25.0 \%) \\
1(2.8 \%)\end{array}$ & $\begin{array}{r}20(52.6 \%) \\
17(44.7 \%) \\
3(7.9 \%)\end{array}$ & $\begin{array}{r}21(67.7 \%) \\
9(29.0 \%) \\
1(3.2 \%)\end{array}$ & $\begin{array}{l}9(50.0 \%) \\
5(27.8 \%) \\
4(22.2 \%)\end{array}$ & 0.16 \\
\hline Other sensitisations (mean number) & 2.3 & 1.8 & 1.7 & 1.3 & 0.11 \\
\hline
\end{tabular}

HDM: house dust mite; ICS: inhaled corticosteroids; $\mathrm{FEV}_{1}$ : forced expiratory volume in one second.

differ significantly between these two groups $(0.10<p<0.59)$.

Dust samples from the mattresses showed that $29.3 \%$ contained no HDM allergens, $30 \%$ montained a low level of HDM allerserts, 25\% contrained an

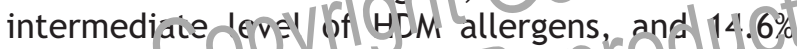
contained a hish le vel of HDM al (engen:

Gender, age, use of long actirig bronchodilating agents, $\mathrm{FEV}_{1} \%$ predicted, smoking status and the number of other sensitisations, did not differ significantly between the exposure groups.

Forty-eight patients (39.0\%) tapered off their dose of ICS over the three months, 53 patients $(43.1 \%)$ remained on the same dose, and 22 patients (17.9\%) had to increase their ICS dosage. Figure 1 shows the percentage of patients who could taper off the dose of ICS, who remained on an equal dose of ICS, and who had to increase the ICS dose after three months in different HDM allergen exposure categories.

Within the 'no' and 'low' exposure group there is a statistically significant difference between the numbers of patients tapering off their ICS dose, those remaining on the same dose and those who increased their ICS dose.

There is a trend in that the higher the exposure to HDM allergens, the higher the proportion of patients who had to increase their dose of ICS. When tested for linear trend, this trend was not significant $(p=0.055)$. Trend analyses showed no significance for tapering off and equal

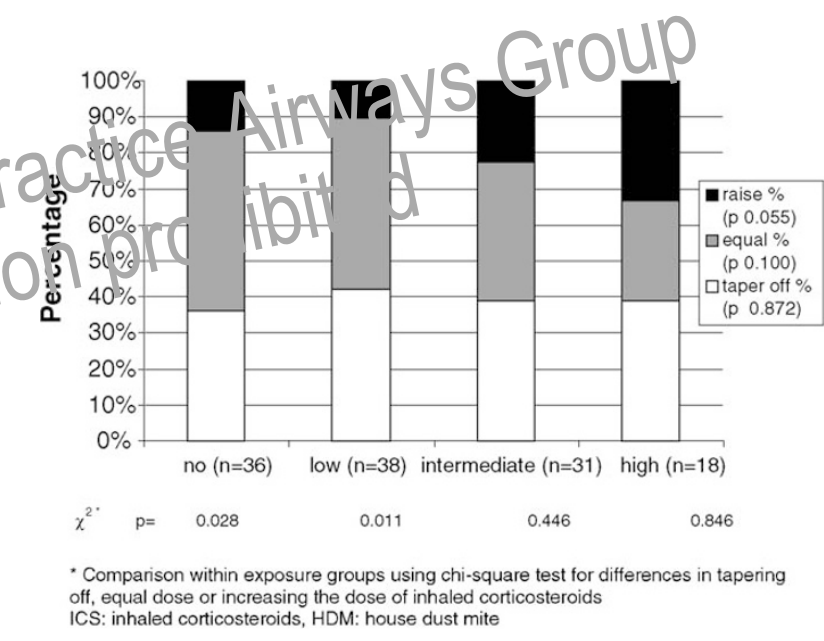

Figure 1 Percentage of patients who could taper off ICS dose, who remained on the same dose, or who had to increase the dose of ICS, according to different categories of HDM allergen exposure.

dose $(p=0.872$ and $p=0.100$, respectively). When performing the analyses without smokers, the same trend was noticed for a larger proportion of patients who increased their ICS dosage when exposed to higher amounts of HDM allergens.

\section{Discussion}

In this observational study we have found that high exposure to HDM allergens can lead to 
use of a higher ICS dosage when HDM-sensitive asthma patients manage their disease according to a self management plan. Because of the relatively high number of current smokers in the high exposure group and the possible negative interaction between smoking and the effect of allergen exposure on the use of ICS, we also performed analyses without the smokers. These data showed the same trend $(p=0.091)$.

No difference was found in the proportion of patients who could taper off ICS dosage according to different HDM allergen exposure levels. We did not expect this finding. The goal of self management programs is to achieve an optimal level of ICS treatment with the lowest possible dose that gives optimal control. We were expecting an overall reduction in the amount of ICS medication required, instead of an increase in the amount of medication used in a substantial part of the study population. This finding raises the question as to whether or not there was under-treatment in the period before starting the self management program. All patients received usual care before the start of the study. The relatively high numbers of patients using intermediate or high dosages of ICS at the start of the observation period do not seem to indicate under-treatment. If exposure to high concentrations of allergens leads to $\tau$ he need for higher doses of ICS avoidarice foeasures regarding these particular all ersens could be useful in reducing tre helecl fo, ics.

The small llumber of patiens $s$ i ientication of this study. In particular, the number of patients in the high exposure group was very low $(n=18)$. This number of patients may have been inadequate to detect a significant difference in ICS use between the exposure groups. As this study was a pilot study, no power calculations were made beforehand.

The observation period of the present study was three months, which is probably not long enough to examine the possibility of tapering off ICS dosages between different HDM allergen exposure groups. It might take a longer period for patients to achieve a steady state of medication use when they are exposed to a specific level of allergens. However, we were especially interested in the first period of self management to see if exposure to a high concentration of HDM allergen might prevent patients from performing the self management plan well because of lack of positive reinforcement. Recruitment took place all year round and patients recruited in different seasons were equally divided over the different exposure groups.

A study using the same self management plan as in the present study showed a saving of more than 200 puffs of ICS per patient over a period of two years in favour of the self management compared to the 'usual care' group [9]. A significantly higher proportion of subjects from the self management group took domestic HDM avoidance measures. This may have contributed to the beneficial effects of the self management program.

We could not correct for exposure to other possible triggers, which might have hampered tapering off of the ICS dose. However, we did exclude patients with a positive RAST for cats or dogs who were keeping these pets.

In the present study the Acarex test was used to determine exposure to HDM allergens. This test is semi-quantitative and it does not distinguish between different mite species. However it has been proven to give reliable information about the presence of HDM allergens in settled dust $[16,17]$. Der p1 is one of the most common HDM allergens. The different exposure groups in this study corresponded more or less with the following concentrations of Der p1 per gram dust: 'none' $\leq 0.33 \mu \mathrm{g} / \mathrm{g}$; 'low' $0.33-2 \mu \mathrm{g} / \mathrm{g}$; 'intermediate' $2-8.33 \mu \mathrm{g} / \mathrm{g}$; and 'high' $\geq 8.33 \mu \mathrm{g} / \mathrm{g}$. Exposure to a concentration higher than $2 \mu \mathrm{g} / \mathrm{g}$ Der $\mathrm{p} 1$ is a risk

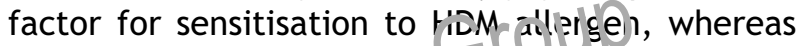
exposure to a confentration higher than $10 \mu \mathrm{g} / \mathrm{g}$ is a majer ris factor al the development of acute astrim in mite-aller yic patients [19]. This might explain why relaty many patients in the low expi) sure group managed to taper off their dose of CS. They are sensitised to HDM allergens, but are exposed to a lower concentration of HDM allergens than the threshold level which is expected to cause symptoms. Patients in the intermediate and high exposure groups were exposed to a concentration of HDM allergen which might induce asthmatic symptoms. This might be the reason why in this group relatively many patients had to increase their dose of ICS. Reducing the exposure to allergens by using allergen avoidance measures (e.g. encasing mattresses and bedding) could prevent the need for increasing the ICS dosage in subjects with a previously high exposure to HDM allergens.

GPs and trained research nurses gave instructions about the self management plan to the patients. The instructions were standardised. A study using the same self management plan showed that there was no influence of the different GPs on the outcome of the intervention as there was a very low intra-cluster correlation [20]. Therefore, we did not expect any difference between the GP-instructed group and the research nurse-instructed group on the outcome of the self management plan. Moreover, the patients of the different instruction groups were comparably divided over the HDM allergen exposure categories 
and the patient characteristics did not differ significantly.

We conclude that in the present observational study, exposure to HDM allergens seems to be associated with the dose of inhaled corticosteroids needed. In particular, this study seems to indicate that exposure to high levels of HDM allergens leads to the need for more ICS when following a self management plan.

This study is, to our knowledge, the first to investigate the relationship between natural exposure to allergens and the need for ICS in asthmatic patients. Although many factors influence the need of ICS, the group of asthma patients exposed to high levels of one important allergen - HDM - showed a higher use of ICS, although this finding was not statistically significant. More research in this area, with information on additional factors influencing medication use, a longer observation period, and a larger study population could lead to better understanding of the relationship between exposure to allergens and medication use.

\section{Acknowledgements, and potential conflict of interest}

This work was supported by a grant for the Netherlands Organisation for icientific Research the Netheriand Astinrna Foundation, Astraterleca $\mathrm{BV}$ and Boetiringer ingelheim

\section{References}

[1] Djukanovic R, Roche WR, Wilson JW, et al. Mucosal inflammation in asthma. Am Rev Respir Dis 1990;142(2):434-57.

[2] Kerstjens HA, Brand PL, Hughes MD, et al. A comparison of bronchodilator therapy with or without inhaled corticosteroid therapy for obstructive airways disease. Dutch Chronic Non-Specific Lung Disease Study Group. N Engl J Med 1992;327(20):1413-9.

[3] Juniper EF, Kline PA, Vanzieleghem MA, et al. Effect of long-term treatment with an inhaled corticosteroid (budesonide) on airway hyperresponsiveness and clinical asthma in nonsteroid-dependent asthmatics. Am Rev Respir Dis 1990;142(4):832-6.

[4] Haahtela T, Jarvinen M, Kava T, et al. Comparison of a beta2-agonist, terbutaline, with an inhaled corticosteroid, budesonide, in newly detected asthma. N Engl J Med $1991 ; 325(6): 388-92$.

[5] Dompeling E, Schayck CP van, Grunsven PM van, et al. Slowing the deterioration of asthma and chronic obstructive pulmonary disease observed during bronchodilator therapy by adding inhaled corticosteroids. A 4-year prospective study. Ann Intern Med 1993;118(10):770-8.

[6] Smeeth L, Boulis M, Hubbard R, Fletcher AE. A population based case-control study of cataract and inhaled corticosteroids. Br J Ophthalmol 2003;87(10):124751.

[7] Kelly HW, Nelson HS. Potential adverse effects of the inhaled corticosteroids. J Allergy Clin Immunol 2003;112(3):469-78, quiz 479.

[8] Gibson PG, Powell H, Coughlan J, et al. Self-management education and regular practitioner review for adults with asthma. Cochrane Database Syst Rev 2003;(1):CD001117.

[9] Thoonen BP, Schermer TR, Boom G van den, et al. Selfmanagement of asthma in general practice, asthma control and quality of life: a randomised controlled trial. Thorax 2003;58(1):30-6.

[10] Custovic A, Taggart SCO, Francis HC, et al. Exposure to house dust mite allergens and clinical activity of asthma. Journal of Allergy and Clinical Immunology 1996;98(1):64-72.

[11] Platts Mills TA, Thomas WR, Aalberse RC, et al. Dust mite allergens and asthma: report of a second international workshop. The Journal of allergy and clinical immunology 1992;89(5):1046-60.

[12] Geijer RMM, Hensbergen W va R, Botcenla BJAM, et al. NHG-Standaard Astma bi Velivasser, $\in$ : Beharideling (NHG Guideline of N:th in: in A duits: Treatment). Huisarts Wet 2) 1 : $14(4): 153-64$.

1137 Global Initiative Ifon is hma: pocket guide for asthma manasson en and provericion. Bethesda: National Institutes (f) -eclth, National Heart Lung and Blood Institute; 1998. Report No.: No. 95-3659B.

[14] Dust mite allergens and asthma: a worldwide problem. International Workshop report. Bull World Health Organ 1988;66(6):769-80.

[15] Bischoff E, Schirmacher W. Investigations of allergencontaining dust samples from the interior of the house. Experientia Suppl 1987;51:189-96.

[16] Pauli G, Tenabene A, Bessot JC, Hoyet C. Guanine dosage in house dust samples and quantification of mite allergens. Experientia Suppl 1987;51:203-9.

[17] Bronswijk JE van, Bischoff E, Schirmacher W, Kniest FM. Evaluating mite (Acari) allergenicity of house dust by guanine quantification. J Med Entomol 1989;26(1):55-9.

[18] Lipworth BJ. Pharmacokinetics of inhaled drugs. Br J Clin Pharmacol 1996;42(6):697-705.

[19] Platts-Mills TAE, Vervloet D, Thomas WR, et al. Indoor allergens and asthma: report of the third international workshop. J Allergy Clin Immunol 1997;100(6):S1-24.

[20] Schermer TR, Thoonen BP, Boom G van den, et al. Randomized controlled economic evaluation of asthma selfmanagement in primary health care. Am J Respir Crit Care Med 2002;166(8):1062-72.

Available online at www.sciencedirect.com science 0 Direct 